\title{
Childlessness and Economic Development: A Survey
}

\author{
Thomas Baudin* David de la Croix ${ }^{\dagger} \quad$ Paula E. Gobbi ${ }^{\ddagger}$
}

January 3, 2019

\begin{abstract}
This paper provides an introduction to the analysis of childlessness, first by describing the stylized facts and the relevant literature, and then by proposing a theoretical framework. We show that both poverty-driven childlessness and opportunity-driven childlessness matter and are essential to a thorough understanding of childlessness as a socioeconomic phenomenon.

Keywords: Childlessness, fertility, education, marriage, children, sterility, economic development, poverty-driven childlessness, opportunity-driven childlessness, female empowerment, childcare, Malthusian economy, educational homogamy, reproductive health, demographic economics, developed countries, developing countries, historical childlessness, quantity and quality of children, inequality.
\end{abstract}

JEL Classification Numbers: J11; O11; O40.

\section{Introduction}

In her book "No Kids: 40 Good Reasons Not to Have Children", Corinne Maier puts into question the idealized notion of parenthood as a natural behavior. She asks her childless readers whether they are prepared to give up their time, money, and friends for the "vicious little dwarves" that will treat them like their servant and end up resenting them. In contrast to Corinne Maier, Jody Day, in her book "Living the Life Unexpected: 12 Weeks to Your Plan B for a Meaningful and Fulfilling Future Without Children", states that "Across the globe, millions of women are reaching their mid-forties without having had a child, (...) most

*IÉSEG School of Management, LEM UMR 9221. Thomas Baudin acknowledges the financial support of the French National Research Agency through the project MALYNES (ANR JCJC).

†IRES, Université catholique de Louvain \& CEPR, London. E-mail: david.delacroix@uclouvain.be. David de la Croix acknowledges the financial support of the project ARC 15/19-063 of the Belgian French-speaking Community.

${ }^{\ddagger}$ ECARES, Université libre de Bruxelles \& CEPR, London. E-mail: pgobbi@ulb.ac.be 
didn't choose this and are silently struggling in a life they didn't foresee. Most people think that women who aren't mothers either couldn't have or didn't want children: the truth is much more complex." In the list of arguments and situations discussed in these two books for the general public, many speak to the theory of fertility as it has been developed since Malthus (1807), Sadler (1830), and Becker (1960).

In this paper, we expose and summarize what can be learned by applying the economic theory of fertility to the understanding of childlessness. We claim that analyzing who is more prone to not having babies, and - more importantly - why, is interesting in itself. Moreover, looking at this specific outcome may help to understand the motives behind fertility behavior in general. In other words, analyzing childlessness behavior helps to unravel the factors behind fertility behavior by adding an additional dimension to the reasoning. For example, if we believe that fertility dropped because of factor $x$, we may wonder whether what we observe in terms of childlessness also squares with this explanation. In technical terms, looking at childlessness in addition to fertility adds restrictions to properly identify the important factors.

Even in historical periods during which demographers would advance that childlessness is identical to sterility, we show that there are patterns which we can learn from. In particular, we will build the case for an economic analysis of childlessness, arguing that childlessness varies both over time and across social classes, independently of the age at first marriage (which is often taken as a proxy for sterility). An unexpected high childlessness rate among the upper classes, which is found both in England and France before the Industrial Revolution, raises many questions about the incentives faced by the upper classes to have children. Developing countries today can also have high levels of childlessness. They are hidden behind general high fertility rates and the common idea that fertility is the result of "mistakes" and a lack of family planning. We show that childlessness can be caused by extreme poverty and therefore act as a kind of Malthusian preventive check. In practice, childlessness that results from poverty is due to malnutrition, stress, unhealthy environments, and venereal diseases leading to infections. We also evidence that poverty is not the only engine of childlessness in developing countries, since progress toward women's empowerment also drives childlessness. Childlessness in developed countries is mostly the result of the high opportunity cost of time. As wages become higher, the cost of childcare also increases which reduces the incentives to have large families, and even to become a parent. Nevertheless, in countries like the US, poverty remains an important driver of childlessness, especially among single women.

After having reviewed the evidence on childlessness in Section 2, we provide a theory to illustrate the main mechanisms described above in Section 3. Such a theory is useful to 
understand how major changes in the environment may affect fertility and childlessness. Such changes include an increase in the education of women, in overall non-labor incomes, and in the degree of assortativeness in the marriage market.

\section{Data}

\subsection{Childlessness in Historical Data}

Very little has been said on childlessness for pre-industrial societies. It is often assumed that being married implied a desire for children, and that the observed childlessness rate is a measure of the natural sterility in a population (Leridon 2008). For England, Wrigley et al. (1997) discuss sterility as a part of their analysis of marital fertility, mainly attributing sterility to biological factors. They argue that the main factor influencing the sterility of married couples, also named entry sterility, was the mother's age at marriage since only 2.6 and 3.8 percent of women who married at ages 15-19 or 20-24 respectively never bore children, whereas 69.3 percent of women who were first married at the age of 40-44 never bore children. Hollingsworth (1965), who studied the demographics of British nobles based on genealogical records, finds an average childlessness rate at 24 percent, based on all persons ever married, a surprisingly high rate compared with other populations and with the average entry sterility rates for English provincial parishes (Wrigley et al. 1997, pp. 395-397).

In a recent paper, de la Croix, Schneider, and Weisdorf (2018) reconsider the English data based on parish records and analyze the social gradient to childlessness using modern econometric techniques. Occupational groups are defined using the professions indicated on the various baptism/marriage/burial registers. In order to compute the childlessness rate (i.e. the share of married couples who never had a child), they use Cox proportional hazard mod-

els to estimate the risk of a married couple having a first birth. Couples become at risk of a first birth upon marriage and censoring occurs when the mother dies. They limit their sample to couples whose burial dates are known to ensure that childlessness is not attributed to couples that migrated out of the parish. Figure 1 shows the predicted childlessness rate ten years after marriage. These childlessness rates are rather high in general. Marriages in wealthier social groups were more likely to remain childless relative to the poor. This result is surprising and difficult to explain, in particular because the age at marriage is very similar across groups. In their paper, the authors consider various mechanisms: higher rates of venereal diseases, higher consanguinity, and the unique cultural context of marriage among the gentry. 


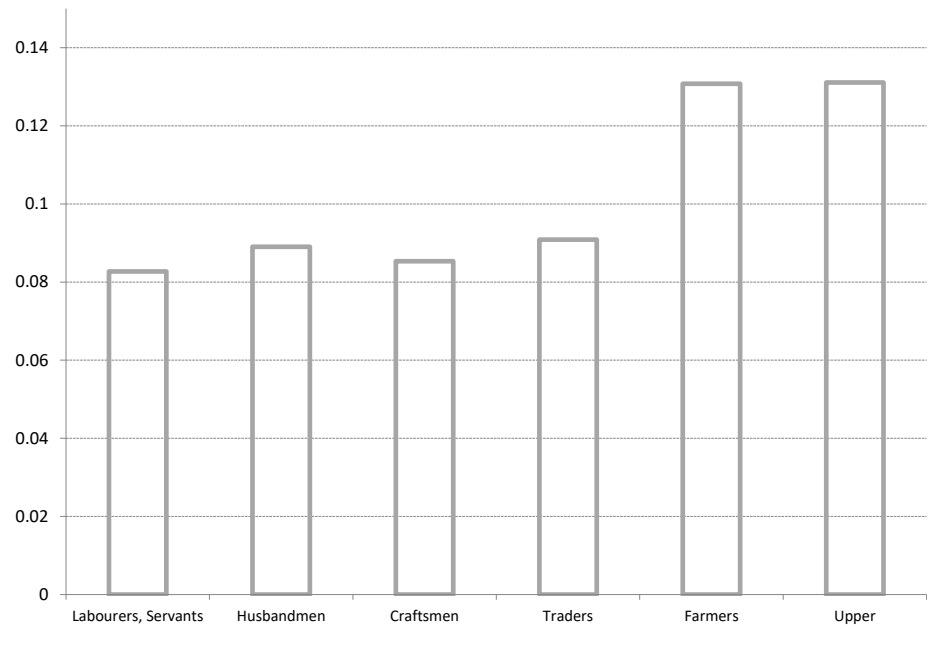

Figure 1: Predicted childlessness rate ten years after marriage by social group - England $1580-1837$

Gobbi and Goñi (2017) look at the childlessness of the British aristocracy in 1650-1882 using the Hollingsworth (2001) database. They show that 30 to $40 \%$ of the peers' daughters who married remained childless around the 1650s (see Figure 2). Compared to the average person in Britain, the childlessness rate of aristocrats was surprisingly high, threatening the continuation of aristocratic family lineages and the maintenance of large estates in the hands of this wealthy elite. Gobbi and Goñi (2017) show that these threats were countered by the introduction of settlements, an inheritance scheme combining primogeniture with a one-generation entail of the land. The typical settlement operated as follows: it was signed between a family's head and his heir upon the marriage of the latter. By signing a settlement, the heir committed to passing down the family estate unbroken to the next generation (Habakkuk 1950). This altered fertility incentives along the extensive margin. In short, those who signed a settlement had to pass down a large inheritance, which they preferred to go to their natural sons rather than to a distant family member. Using genealogical data from Hollingsworth (1964), Gobbi and Goñi (2017) show that families who signed a settlement were more likely to have children than families who failed to sign a settlement because the family's head died before his heir's wedding. Eventually, settlements brought childlessness rates among aristocrats close to the "natural" rate of 2.4 percent (Tietze 1957), and hence, contributed to the survival of noble family lineages.

In France, scholars have explored childlessness and sterility by social class more directly. Bardet (1983), who reconstituted 5,889 complete family histories over the seventeenth and eighteenth centuries, presents a table (p. 300) with the percentage of childless women by 

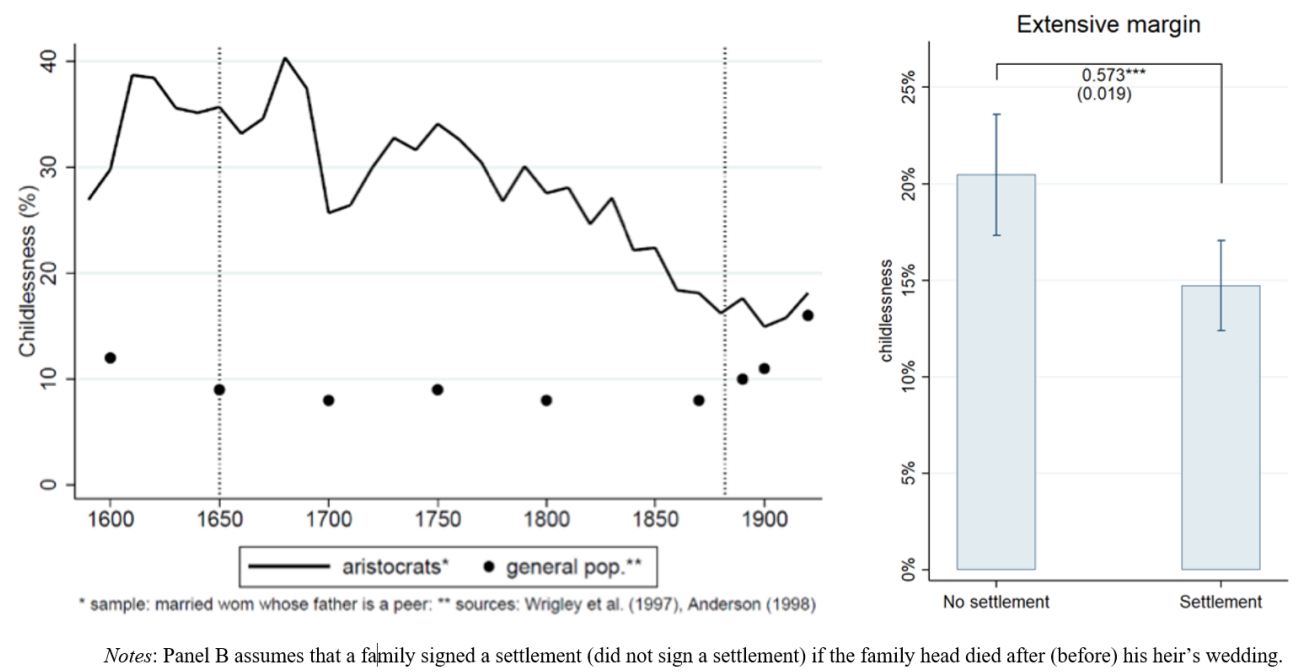

Figure 2: Childlessness rates of British aristocrats by marriage decade

year at marriage and social class. The childlessness rate is computed based on women who married before 30 years old, and for whom a complete record of life events exists. Bardet's numbers are presented in Table 1 . The social gradient was positive: childlessness was more widespread among nobles and shopkeepers than among workers, and there was a positive time trend in the data. On the whole, Bardet's figures are above the natural sterility rate estimated elsewhere (Leridon 2008).

\begin{tabular}{lccccc}
\hline \hline & \multicolumn{2}{c}{ Social Classes } & \multicolumn{2}{c}{ Difference } \\
Marriage & Gentry & Shopkeepers & Craftsmen & Workers & Gentry - Workers \\
$1670-1699$ & 4 & 4 & 5 & 3 & 1 \\
$1700-1729$ & 8 & 9 & 7 & 6 & 2 \\
$1730-1759$ & 11 & 11 & 8 & 6 & 5 \\
$1760-1792$ & 12 & 13 & 10 & 8 & 4 \\
$\Delta 1670-1792$ & +8 & +9 & +5 & +5 & \\
\hline \hline
\end{tabular}

Note: first line should be read as: $4 \%$ of the women belonging to the gentry who married before age 30 during the period 1670-1699 remained childless, etc. The last column gives the difference between the childlessness rate of the gentry and that of the workers. The last line computes the difference between the fourth line (1760-1792) and the first line (1670-1699).

Sources: Bardet (1983) p300, author's own calculations

Table 1: Childlessness rate by year of marriage and social class

Taking a fresh look at Bardet's data, de la Croix and Brée (2019) ponder the possible explanations for the rise in childlessness witnessed. Any explanation should also be compatible with the drop in fertility observed over this period, and with the increase in education (as 
indicated by the increase in the number of people able to sign the marriage register). They find that several explanations appear irrelevant due to the absence of change during the period under consideration: contraception, wet nursing, age at marriage, income, and divorce. Other explanations have been rejected because they are not consistent with the fact that changes were more pronounced among the higher social groups; they include: drop in mortality and rising secularization. As such, three explanations without any direct evidence for or against them remain: increase in materialism, women's empowerment, and increase in return to education.

A possible increase in the return to education as a driver of the drop in fertility is rejected on the basis of a theoretical argument. If the return to education had increased, a drop in fertility should have been observed, which fits the data well, but also a drop in childlessness, as having children would have become more worthwhile. Indeed, with a higher return to education, children have a brighter future, and hence become more valuable. There is a counterargument to this claim: giving birth to one child that is left uneducated becomes less worthwhile from an individual perspective and less acceptable from a social perspective if the return to education rises. Thus, many very poor women who cannot afford to send their children to school might choose to stay childless instead of giving birth to one child who will then remain uneducated. This, in isolation, would increase childlessness in case of an increasing return to education, in particular in the low social classes, which is an implication rejected by the data as it is mostly the upper classes for which childlessness increases. A last argument in favor of the rise in the return to education storyline is that it could lead to a reduction in the desired number of children and/or to a postponement of fertility as mothers educate themselves longer. Since there is a stochastic element in having children, reducing the number of desired children or postponing childbirth both increase the risk of ending up childless. This explanation might be relevant for the most recent periods when the mean age at motherhood has increased above 30 , but not for the preindustrial era.

Thus, two explanations remain to understand this increased childlessness: the increase in materialism and women's empowerment. The first - increase in materialism - means an increasing availability, variety, affordability, and quality of consumer goods, implying a rising demand for them. According to De Vries (2008), such a change is a key characteristic of Northern Europe for the period from the mid-seventeenth century to about 1830. De Vries (2008) documents that many households began to consume a wider variety and amount of consumer goods, accompanied by an intensification of household labor and engagement with different aspects of the market. Even if an increase in materialism may explain why households desired fewer children, could it also explain why some of them even stopped 
wanting children altogether? Did certain kinds of new (luxury) goods become accessible or desirable, and was being childfree a requirement to procure them? Van de Walle and Van de Walle (1972) identify two major arguments that were advanced by authors of the eighteenth and nineteenth centuries to explain why women did not want children. The first of these arguments is that women did not want to experience the physical changes of pregnancy, and the second was that women wanted to preserve their freedom and avoid the burden of a pregnant belly. Implicit in these two arguments is the desire to avoid losing one's place in society - not to be kept away from salons and high society. This would then only have concerned the elite.

The second - women's empowerment - can be measured along several dimensions, and each dimension has its own effect on fertility (see de la Croix and Vander Donckt (2010)). Essential dimensions in today's economies are: political empowerment, educational attainment, economic participation and opportunity, as well as health and survival. On the whole, there is converging evidence that the gender gap in Rouen started to shrink along the educational, occupational, and health dimensions during the eighteenth century. This may have reduced fertility and increased childlessness as long as women inherently desired fewer children than men. For educational attainment, marriage registers can be used to evaluate the basic level of literacy through the quality of someone's signature. de la Croix and Brée (2019) show that the educational gap between (married) men and women shrunk over the period. With regard to the gender gap in economic participation and opportunity, de la Croix and Brée (2019) use the database of famous people built by de la Croix and Licandro (2015) and show that prior to the eighteenth century, only a few women were famous in Rouen. Then, the share of women among famous people increased to $10 \%-12 \%$. Although some of the new occupations held by women do not necessarily correspond to our idea of highly skilled jobs (like playing the role of a soubrette on stage, for example), it is fair to conclude that the gender gap in economic participation and opportunity started to shrink in the eighteenth century.

Four recent papers stress the importance of economic determinants for US data from a historical perspective. Gobbi (2013) shows how childlessness rates and fertility rates comove over time as a function of shocks to the gender wage gap and to the cost of having children. Aaronson, Lange, and Mazumder (2014) focus on a quantity-quality trade-off faced by parents and look at how the Rosenwald Rural Schools Initiative in the early twentieth century affected fertility along both the extensive and intensive margins. They show that the expansion of schooling opportunities decreased the price of child quality. This reduction in the price of child quality decreased the proportion of women with the highest fertility rates as 


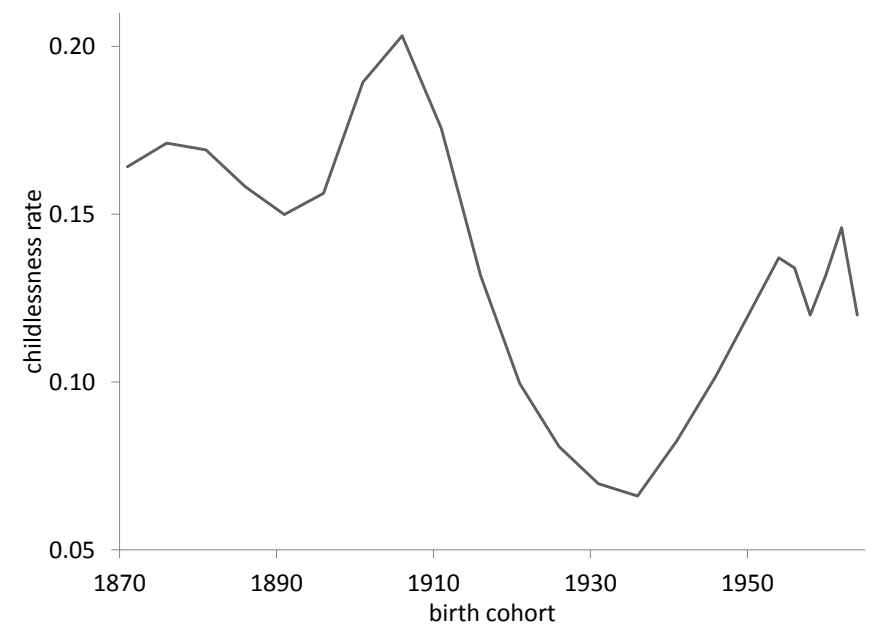

Figure 3: Childlessness rates of married women in the United States by birth cohort

expected, but it also led to a decrease in childlessness rates. Baudin, de la Croix, and Gobbi (2015) provide a framework to understand the deep causes of childlessness and how their importance has changed over time. As shown in Figure 3 from US census data, childlessness rates were high in the past, decreased and then increased again for more recent cohorts of married women. Baudin, de la Croix, and Gobbi (2015) apply structural estimation techniques to historical census data on fertility for the United States, over the period 18711964. They evidence that the first drop in childlessness rates for the cohorts of women born between 1910-1935 is due to a decrease in the number of women who remained childless because of poverty, while the increase that followed is due to a rise in the opportunity cost to rear children. The main causes of childlessness over the past 100 years have changed from poverty-induced necessity to a choice driven by higher levels of income and education among women.

Finally, Bhalotra, Venkataramani, and Walther (2018) study the impact of the introduction of Sulfa drugs in the United States in 1937 on fertility and childlessness. The introduction of antibiotics reduced child and maternal mortality dramatically. By encouraging the postponement of first births and female labor force participation, this revolution has led to a significant increase in childlessness among American women. This explanation is complementary to that of Baudin, de la Croix, and Gobbi (2015), as freeing women's time to participate in the labor force contributes to the increase in female education and wages. 


\subsection{Childlessness in Developing Countries}

Developing countries remain heterogeneous regarding their demographic situations: some countries like Brazil have almost achieved their demographic transition (Turra and Queiroz 2005), while others like Nigeria are experiencing the early phases of the latter (Canning, Raja, and Yazbeck 2015). Thus, contrary to developed countries, it is impossible to provide a unified picture of the dynamics of childlessness along the demographic transition of developing countries. For this reason, Baudin, de la Croix, and Gobbi (2019) propose a cross-country analysis of the relationship between childlessness and development. They develop a theoretical framework distinguishing between four types of childlessness. Natural sterility reflects situations in which a woman or a couple suffers from an innate biological impossibility of having children; this kind of childlessness is unrelated to the level of education or wealth. Mortality-driven childlessness concerns women who have had children, but none of them have survived. Opportunity-driven childlessness comes from the economic opportunities offered to a couple and especially to women: the more educated a woman, the higher her potential wage and thus the higher the opportunity cost of the time she does not spend in the labor force. ${ }^{1}$ Finally, poverty-driven childlessness concerns women who face the heaviest burden of poverty; lack of education and celibacy are important drivers of this kind of childlessness.

The co-existence of poverty- and opportunity-driven childlessness explains why the relationship between the rates of definitive childlessness and the development level of a country is weak a priori. Proxying development by the average level of education of the population, we evidence this in the left panel of Figure 4. The weak link between childlessness and development hides a powerful statistical regularity: along the development process, poverty-driven childlessness is progressively replaced by opportunity-driven childlessness. Such a regularity has been conjectured in an alternative framework by Poston and Trent (1982).

As a result, any economic shock or development policy affecting poverty and the economic opportunities offered to women may have an ambivalent effect on the dynamics of childlessness in developing countries. This is what Baudin, de la Croix, and Gobbi (2019) evidence in a series of quantitative analyses. For instance, enforcing strict wage equality between men and women would, not surprisingly, reduce the fertility of women with children as higher wages translate into a higher opportunity cost of having children. This increase in the opportunity cost of having children translates into higher childlessness rates among highly educated women. In most cases, this increase is not compensated fully by the decrease in

\footnotetext{
${ }^{1}$ The theoretical frameworks of Gobbi (2013) and Aaronson, Lange, and Mazumder (2014) focus on this type of childlessness.
} 

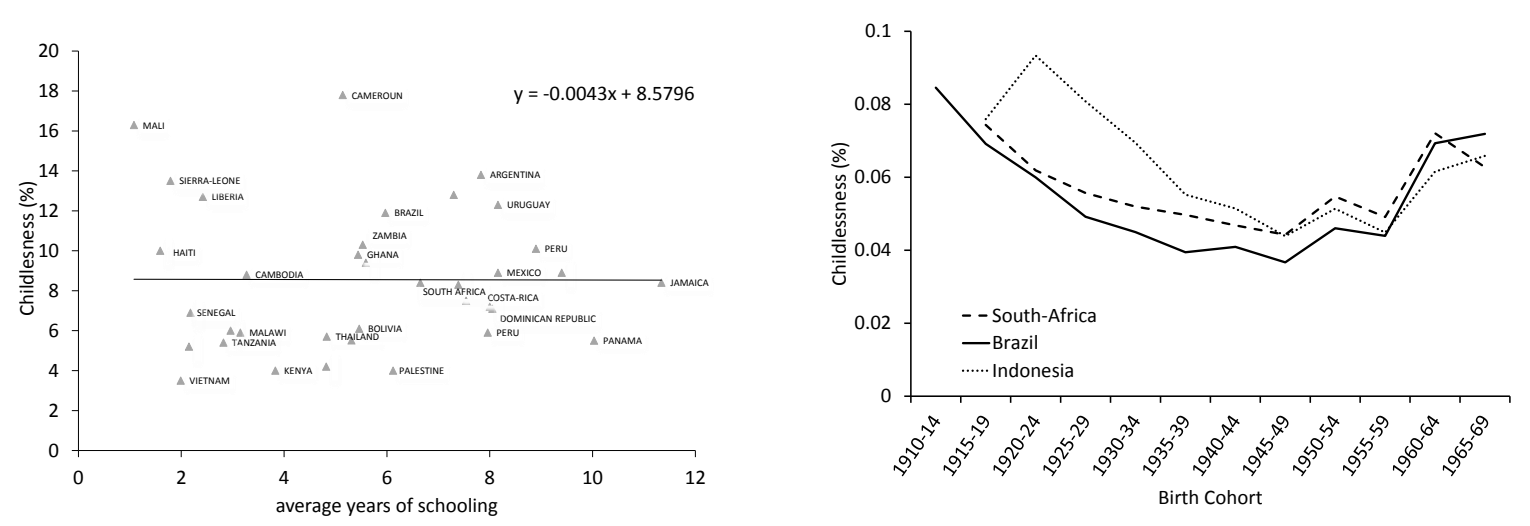

Figure 4: Left panel: Relationship between definitive childlessness rates and the average level of education of women aged between 40 and 54 in a set of 36 developing countries. Data from Baudin, de la Croix, and Gobbi (2019). Right panel: definitive childlessness among married women by cohort of birth. Data from IPUMS-International, authors' own calculations.

childlessness due to poverty: low-educated women become richer and thus less subject to extreme poverty leading to sterility. The general increase in childlessness rates magnifies the decrease in fertility among mothers. On a set of 36 developing countries, they estimate that closing the gender wage gap would reduce the fertility of mothers by $8.21 \%$, while after taking into account the adjustment of childlessness and marriage rates, the total decrease in fertility would equal $12.97 \%$.

In a study on India, Baudin and Sarkar (2018) confront the fact that the highest childlessness rates are found in the most developed states and among highly educated women to the belief that childlessness in India is synonymous with sterility. They identify a U-shaped relationship between the probability for a woman to end her reproductive life childless and her level of education. This statistical regularity remains valid after controlling for the specific context of caste divisions, religious diversity, as well as state and cohort fixed effects. It reveals that opportunity-driven childlessness is emerging as a new and important form of childlessness in the country. Interestingly enough, the education of husbands reduces the probability of remaining childless, which highlights the persistence of traditional family structures in which the male breadwinner protects women against extreme forms of poverty. In a recent paper, using alternative vocabulary, Iftikhar (2018) also identifies the co-existence of poverty and opportunity-driven childlessness in Pakistan, a country that shares many specificities with India.

While all developing countries have not finished their demographic transition, some of them are at very advanced stages of the latter. This is the case, for instance, of Brazil, Indonesia, 

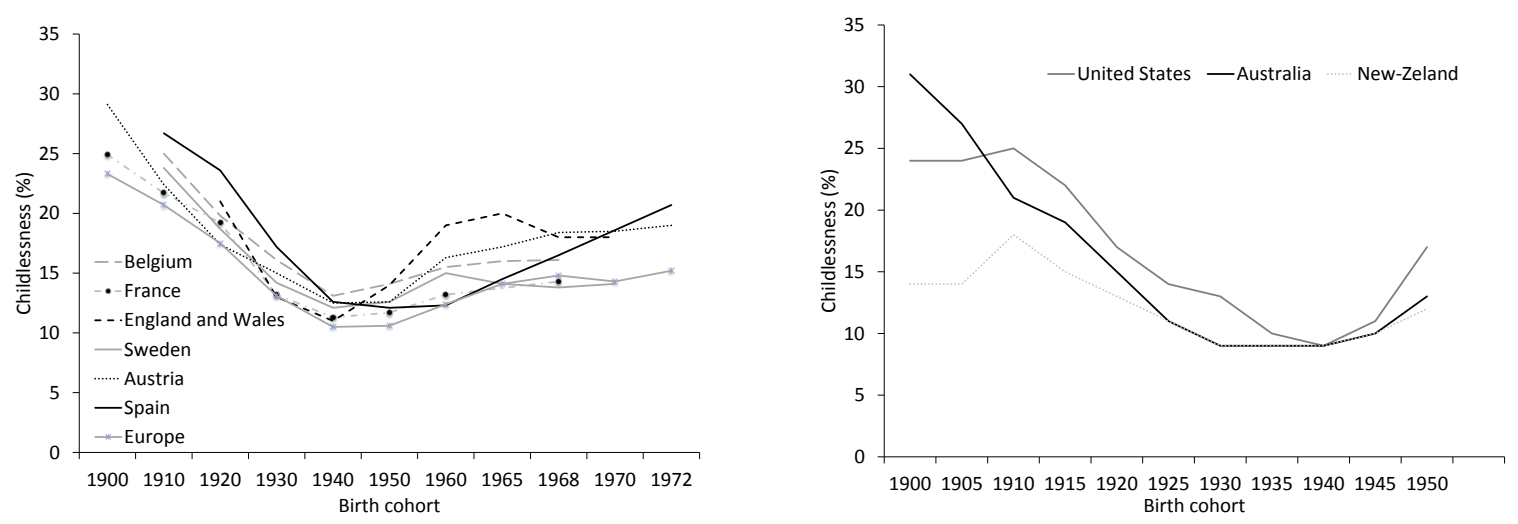

Figure 5: Left panel: Childlessness rates at age $40+$ among European women by cohort of birth. Data from Sobotka (2017). Right panel: childlessness rates among all women at age 45, data from Rowland (2007).

and South Africa, three large countries which are emblematic of their continents. On the right panel of Figure 4, we document the evolution of definitive childlessness rates by birth cohort among married women between 1915 and 1965. The U-shaped pattern of childlessness is remarkable and puts these three countries in a situation close to a large set of developed countries, as shown in the next section.

\subsection{Childlessness in Developed Countries}

The cohorts of women born in developed countries over the course of the twentieth century have experienced rapid changes in the prevalence of definitive childlessness. In Figure 5, we document a pattern of childlessness, which is systematically U-shaped in developed countries.

In their study of childlessness in the US, Baudin, de la Croix, and Gobbi (2015) identify three major reasons for being childless: natural sterility, poverty-driven childlessness, and opportunity-driven childlessness. As explained in Subsection 2.1, their theoretical framework allows to reproduce the evolution of childlessness rates in the US in the twentieth century both quantitatively and qualitatively. Beyond this, it also enables to understand what drives the relationship between education and childlessness for a given year. In 1990, American women of age 45-70 were characterized by a U-shaped relationship between their childlessness rate and their education level (see Figure 6, left panel). As shown in Figure 6 (right panel), this fact remains valid even when they disaggregate their data at the cohort level, the same being true for racial differences. It testifies to how, in the richest country in the world, poverty-driven childlessness continues to co-exist with opportunity-driven child- 


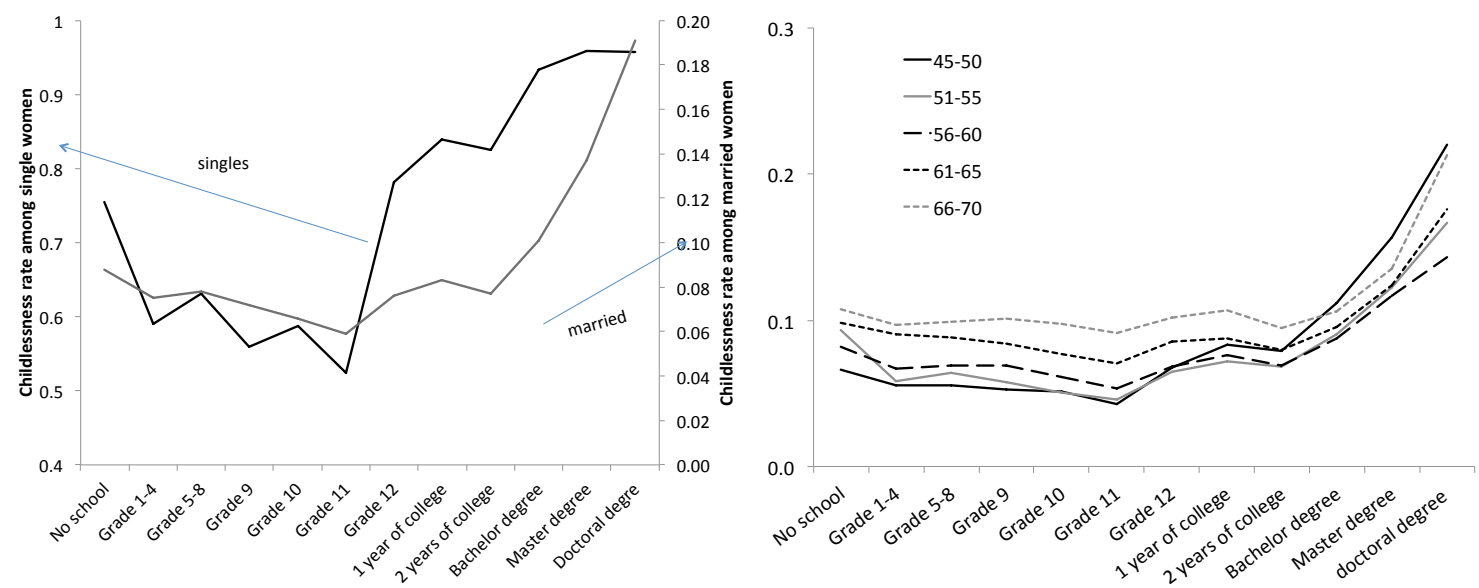

Figure 6: Left panel: Childlessness rates at age 45-70 among American women in 1990. Right panel: Definitive childlessness rates among American women by cohort of birth, data from Baudin, de la Croix, and Gobbi (2015).

lessness. Baudin, de la Croix, and Gobbi (2015) estimate that in 1990 in the US, 2.5\% of American women were definitively childless because of their poverty, but this percentage increases to $12.1 \%$ among women with less than 5 years of schooling. On the other side, $8.9 \%$ of American women were childless because of the economic opportunities offered to them, and this percentage reaches $19.4 \%$ among women with at least a bachelor's degree.

The persistence of high levels of childlessness among poor women is associated with the persistence of strong economic inequalities in the country. The authors show, in a counterfactual experiment, how an increase in the returns to schooling and its associated rise in the Gini coefficient of labor and non-labor income may increase the rates of poverty-driven childlessness. An increase in the rate of return of one year of schooling from $9.2 \%$ to $12.6 \%$ could increase the prevalence of poverty-driven childlessness among American women from 2.5 to $3.3 \%$.

The educational gradient of childlessness in the US is remarkable; this is also the case in countries like England and Germany. Berrington (2017) documents a positive educational gradient of childlessness among English women aged 40-49 born between 1940 and 1969 . The absence of a negative educational gradient for low levels of education may be explained, among other factors, by the fact that women are grouped in too large educational groups which does not allow to identify the poorest women. See Baudin, de la Croix, and Gobbi (2015) for a discussion of that point. The case of Germany is one of the most interesting. Using micro-census data from 2012, Kreyenfeld and Dirk (2017) evidence a positive educational gradient of definitive childlessness among women born between 1940 and 1964 in 
former West Germany. Among their counterparts from East Germany, childlessness has a U-shaped relationship with education, whatever the sub-cohort observed and even if education is grouped in very large categories. As shown by Baudin and Stelter (2018a), this is a unique opportunity to appreciate how historical, institutional, and economic factors shaping the level of economic and health poverty in turn shape the structure of childlessness in a population.

\section{Models}

The goal of this section is to illustrate theoretically how an economic shock like an increase in women's education or a change in the degree of assortativeness on the marriage market may change childlessness rates. Here, we build a new version of Baudin, de la Croix, and Gobbi (2015)'s framework in which childlessness can only be of two types: poverty driven or opportunity driven. As in Aaronson, Lange, and Mazumder (2014) and Bhalotra, Venkataramani, and Walther (2018), we introduce a trade-off between the quality and quantity of children. In Subsections 3.1 to 3.3 , we analyze the properties of a model without marriage. We investigate the relationship between marriage and childlessness in Subsection 3.4.

We assume that each woman is characterized by the following utility function:

$$
u\left(c, n, h^{\prime}\right)=\ln c+\alpha \ln (n+\nu)+\beta \ln h^{\prime},
$$

where $c$ denotes the consumption of an aggregated good whose price is normalized to $1 . n$ denotes the number of children this woman gives birth to, while parameter $\nu>0$ allows for the existence of corner solutions on $n$. Variable $h^{\prime}$ denotes the quality of children, it takes the form of human capital in most of the literature. $\alpha$ and $\beta$ are preference parameters over fertility and child quality, respectively.

Following de la Croix and Doepke (2003), we assume that the quality of children is produced through an investment in education, $e$; it also depends on the parental human capital, $h$, such that:

$$
h^{\prime}=(e+\pi)^{\phi} h^{\iota} \quad, \quad \text { with }\{\phi, \iota\} \in \mathbb{R}^{2+}
$$

where $\pi>0$ allows for the possibility of not educating children, $\phi$ captures the weight of education in the production of human capital, and $\iota$ captures the intergenerational transmission of human capital.

As in Baudin, de la Croix, and Gobbi (2015), we assume that women cannot have children 
if their consumption is lower than a threshold, $\hat{c}$ :

$$
c \leq \hat{c} \Rightarrow n=0 \text {. }
$$

This constraint introduces poverty-driven childlessness in a simple way as all women who are too poor to afford a consumption bundle of $\hat{c}$ will be childless. Women maximize their utility with respect to $c, n$, and $e$, subject to this minimum consumption constraint and the budget constraint:

$$
c+\rho e=(1-\tau n) w+\Omega
$$

where $\rho>0$ denotes the cost of providing one unit of education to all children within the family. We make a somewhat unusual hypothesis as we assume that education is a pure public good inside the family. This is done for the sake of simplicity, but it will not change the main feature of our model compared to the more usual model in which education is considered as a pure private good inside the family. ${ }^{2} \Omega>0$ is a non-labor income orthogonal to $h$ and $w$, the wage rate earned by the woman on the labor market. ${ }^{3}$ A woman's potential wage is an increasing function of her human capital $h$. Finally, $\tau$ denotes the time that raising and bearing a child requires, time that cannot be spent in the labor force.

We assume that, if $\tau$ is positive, then $\tau \nu>\alpha$ in order to ensure that not having children may be an optimal decision. ${ }^{4}$ In the following subsections, we impose restrictions on the set of parameters in order to analyze poverty- and opportunity-driven childlessness separately. Relaxing all these restrictions at the same time would impose a large number of other restrictions in order to guarantee the existence of solutions to this problem. In the end, it would be possible to determine state-spaces where each of the properties presented in what follows would prevail.

\footnotetext{
${ }^{2}$ In technical words, the cost of providing one unit of education to $n$ children is equal to $\rho e$; it does not depend on $n$. Most of the literature assumes that the cost of providing one unit of education to $n$ children equals $\rho n e$. Our assumption does not change our main results qualitatively as it does not prevent the existence of a trade-off between the quality and the quantity of children. See Baudin (2011) and Baudin (2012) for a generalization.

${ }^{3}$ As shown in Jones, Schoonbroodt, and Tertilt (2010), because of the log specification of the utility function, a positive non-labor income ensures the negative fertility-income relationship at the aggregate level. As mentioned by them, this could be gifts, lottery income, or bequests.

${ }^{4}$ The condition $\tau \nu>\alpha$ should be read as follows: for a given $\nu$, the time cost of having children has to be high enough; while for a given $\tau$, the reservation utility in case of childlessness should be high enough.
} 


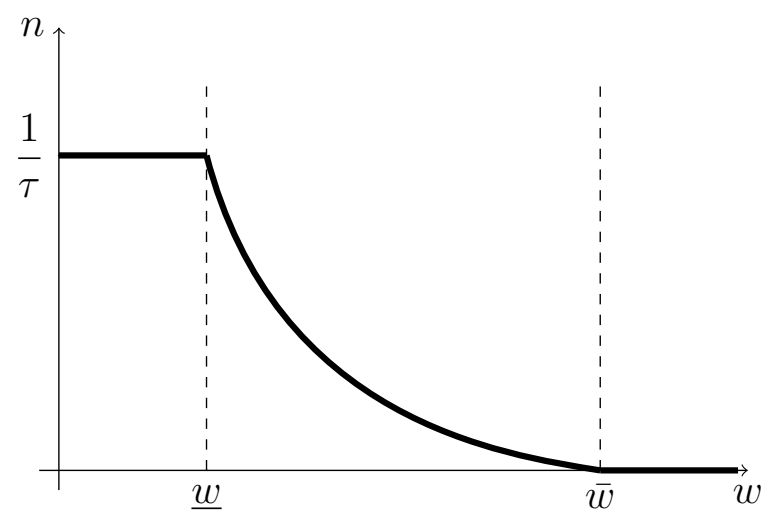

Figure 7: Opportunity-driven childlessness

\subsection{Opportunity-Driven Childlessness: $\hat{c}=\beta=0$}

This first version of the model abstracts from both investments in education $(\beta=0)$ and poverty-driven childlessness $(\hat{c}=0)$, while it focuses on opportunity-driven childlessness $(\nu>0)$. Each woman maximizes her utility function (1) subject to her budget constraint (4). Then:

$$
c^{*}= \begin{cases}\Omega & \text { if } w \leq \frac{\alpha \Omega}{1+\tau \nu} \equiv \underline{w} \\ \frac{(1+\tau \nu) w+\Omega}{1+\alpha} & \text { if } w \in] \frac{\alpha \Omega}{1+\tau \nu}, \frac{\alpha \Omega}{\tau \nu-\alpha}[ \\ w+\Omega & \text { if } w \geq \frac{\alpha \Omega}{\tau \nu-\alpha} \equiv \bar{w}\end{cases}
$$

and

$$
n^{*}= \begin{cases}\frac{1}{\tau} & \text { if } w \leq \underline{w} \\ \frac{\alpha}{1+\alpha} \frac{(1+\tau \nu) w+\Omega}{\tau \nu}-\nu & \text { if } w \in] \underline{w}, \bar{w}[ \\ 0 & \text { if } w \geq \bar{w} .\end{cases}
$$

In the interior regime, an increase in women's wages raises the opportunity cost of having children, inciting women to substitute private consumption to the quantity of children. This mechanism prevails only when the wage level is high enough $(w>\underline{w})$ to prevent situations in which mothers' fertility is limited by their reproductive capacity. In the latter situation, already documented by de la Croix and Doepke (2003) for instance, any wage increase has no effect either on fertility or on consumption, as women do not participate in the labor force.

When their wage becomes very large $(w>\bar{w})$, the relative cost of having a child becomes so 
high that specializing in labor market activities and being childless becomes optimal. This is what we call opportunity-driven childlessness.

Let us consider a situation in which women are heterogeneous regarding their level of education. Any policy making higher education more prevalent would translate into a higher proportion of women enjoying higher levels of education, better economic opportunities, and thus higher costs of having children. This will translate in the end into an increase in the proportion of women who are childless because of good economic opportunities. As documented by Baudin, de la Croix, and Gobbi (2015), more largely, any policy raising women's wages, like closing the gender wage gap, would increase opportunity-driven childlessness.

In this framework, opportunity-driven childlessness appears quite mechanical. In richer models like de la Croix and Pommeret (2018), opportunity-driven childlessness is driven by postponement decisions. In such a set-up, for a given age, highly educated women are those enjoying the best economic opportunities, they thus have the strongest incentives to postpone their first birth. In cases where women are confronted to an especially positive series of economic opportunities, serial postponement may lead either to the inability to have children as fecundity recedes with age, or to the decision to remain childless. Even if richer, the main prediction of this model regarding the effect on childlessness of offering better economic opportunities to women is not different from that obtained with the model developed in this chapter.

\subsection{Poverty-Driven Childlessness: $\beta=\nu=0$}

In this specification of the model, we abstract again from the quality-quantity trade-off $(\beta=0)$ and rule out opportunity-driven childlessness $(\nu=0)$, but we now let poverty-driven childlessness exist $(\hat{c}>0)$. This specification of the model requires redefining the utility function in the specific case where $n=0$. We then assume that $u\left(c, 0, h^{\prime}\right)=\ln c-P$, where $P>0$ is an arbitrarily large parameter such that $u\left(c, 0, h^{\prime}\right)<u\left(\hat{c}, n, h^{\prime}\right) \forall n>0$. It ensures that $(i)$ the utility function remains defined even if not differentiable when $n=0$, and $(i i)$ not having children is never a rational decision.

Non-labor income becomes a crucial driver of behaviors as it determines the capacity of women to consume the minimum consumption bundle $\hat{c}$ in extreme situations in which their wages are very small and/or they do not participate in the labor force.

Case 1: $\Omega \in] 0, \hat{c}]$ 


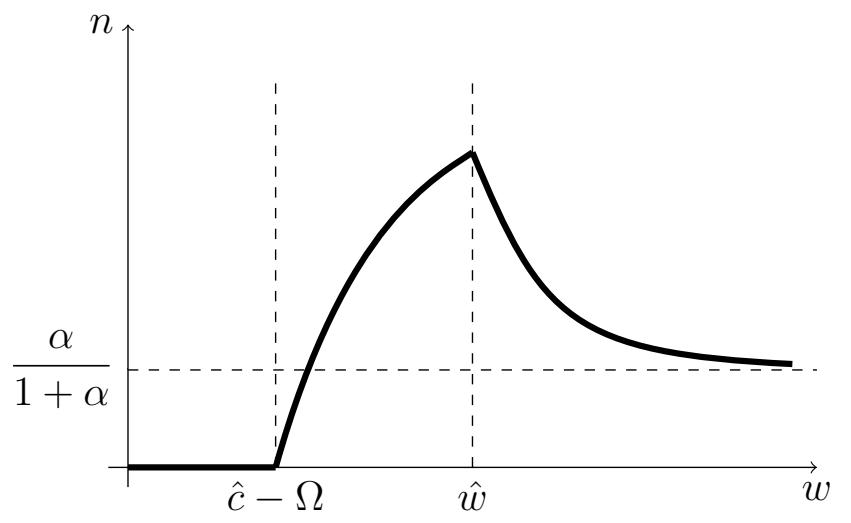

Figure 8: Poverty-driven childlessness when non-labor income is low $(\Omega \in] 0, \hat{c}])$.

In this situation, the non-labor income is below $\hat{c}$. Hence, participation in the labor force is a necessary but not sufficient condition for a woman to afford to have children. Let us define $\hat{w}$ as the minimum wage such that the minimal consumption constraint (3) does not bind: $\hat{w} \equiv(1+\alpha) \hat{c}-\Omega$. Individual behaviors are described as follows:

$$
c^{*}= \begin{cases}w+\Omega & \text { if } w \leq \hat{c}-\Omega \\
\hat{c} & \text { if } \left.w \in] \hat{c}-\Omega, \hat{w}] \quad \text { and } \quad n^{*}=\left\{\begin{array}{ll}
0 & \text { if } w \leq \hat{c}-\Omega \\
\frac{w+\Omega}{1+\alpha} & \text { if } w>\hat{w}
\end{array} \quad \text { if } w \in\right] \hat{c}-\Omega, \hat{w}\right] \\
\frac{\alpha}{1+\alpha} \frac{w+\Omega}{\tau w} & \text { if } w>\hat{w} .\end{cases}
$$

Equation (5) shows that low-educated women who earn low wages end up childless because of their poverty, which is what we call poverty-driven childlessness. Importantly, the reproductive constraint for having children also gives rise to a Malthusian type of fertility regime. Women with an intermediate wage level and low non-labor income, limit their consumption to $c=\hat{c}$, and any increase in their wage translates into a higher fertility. Once the constraint on $\hat{c}$ does not bind anymore, individual behaviors are aligned with classical Beckerian theory in which higher wages decrease the optimal number of children a woman has.

From Equation (5) and Figure 8, it is clear that, for a given distribution of educational levels among women, any transfer policy increasing $\Omega$ would reduce $\hat{w}$ and thus childlessness rates. Nevertheless, the net effect of such a policy on average fertility is ambiguous as the fertility of mothers would increase in the meantime. This simple mechanism highlights how important it is to consider the adjustment of childlessness when one wants to understand how economic and family policies change fertility. This issue is extensively discussed in Baudin, de la Croix, 


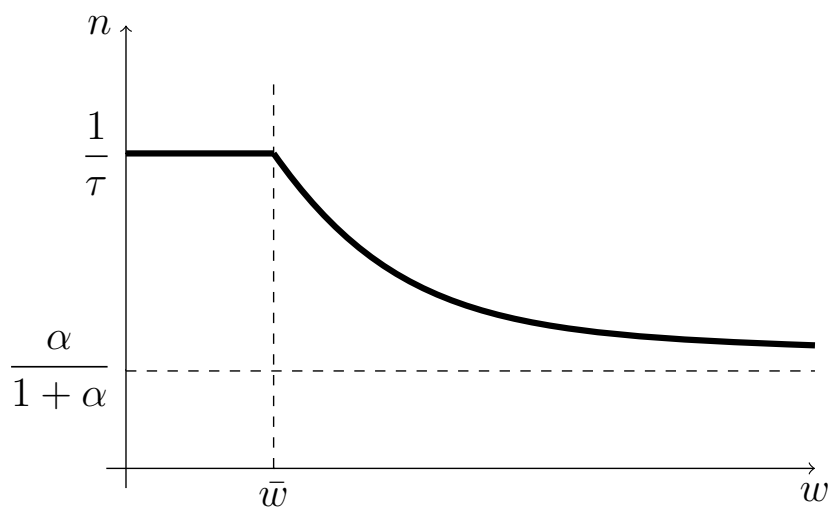

Figure 9: Fertility when non-labor income is high $(\Omega>\hat{c})$.

and Gobbi (2019).

Case 2: $\Omega>\hat{c}$

When the non-labor income is higher than the minimum consumption that allows a woman to bear a child, poverty-driven childlessness disappears. Furthermore, the Malthusian regime described in the previous sub-case also disappears. From the budget and time constraints, two possible regimes remain, respectively: an interior regime in which no other constraint than the budget constraint binds and a corner solution in which fertility is maximal. We then obtain the following optimal solutions:

$$
c^{*}=\left\{\begin{array}{ll}
\Omega & \text { if } w \leq \alpha \Omega \equiv \bar{w} \\
\frac{w+\Omega}{1+\alpha} & \text { if } w>\bar{w}
\end{array} \quad \text { and } \quad n^{*}= \begin{cases}\frac{1}{\tau} & \text { if } w \leq \bar{w} \\
\frac{\alpha}{1+\alpha} \frac{w+\Omega}{\tau w} & \text { if } w>\bar{w}\end{cases}\right.
$$

In this situation where poverty-driven childlessness does not exist, an increase in the nonlabor income increases fertility along its intensive margin in the interior regime only.

\subsection{Quality/Quantity Trade-Off: $\beta>0, \nu>0, \hat{c}=0$}

In this specification of the model, we rule out poverty-driven childlessness and authorize the existence of opportunity-driven childlessness. We extend our framework to investments in the human capital of children. ${ }^{5}$ As explained earlier, we assume, without loss of generality,

\footnotetext{
${ }^{5}$ For the sake of space and simplicity, we do not analyze the specification of the model in which investing in human capital is possible, while opportunity-driven childlessness does not exist but poverty-driven childlessness does. Baudin and Stelter (2018b) study such a framework allowing, furthermore, for the existence of agricultural and industrial goods.
} 
that economies of scale in human capital accumulation are maximum as education is a public good inside the family.

Depending on the values of the parameters, many regimes may prevail in this configuration of the model. In addition to the budget constraint, three constraints may bind: $n \geq 0, e \geq 0$, and $n \leq \frac{1}{\tau}$. For a given value of wages $w$ and non-labor income $\Omega$, from none to two of them may bind simultaneously. ${ }^{6}$

Proposition 1 There exists a non-empty state-space $\mathcal{H}=\{\tau, \nu, \alpha, \beta, \rho, \phi, \iota, \hat{c}\}$ such that the optimal decisions of the representative individual are described as follows:

$$
\begin{aligned}
& c^{*}= \begin{cases}\Omega & \text { if } w \leq \underline{w} \\
\frac{(1+\tau \nu) w+\Omega}{1+\alpha} & \text { if } \left.w \in] \underline{w}, w_{e}\right] \\
\frac{(1+\tau \nu) w+\rho \pi+\Omega}{1+\alpha+\phi \beta} & \text { if } \left.w \in] w_{e}, w_{n}\right] \\
w+\Omega & \text { if } w>w_{n},\end{cases} \\
& n^{*}= \begin{cases}\frac{1}{\tau} & \text { if } w \leq \underline{w} \\
\frac{\alpha}{1+\alpha} \frac{(1+\tau \nu) w+\Omega}{\tau w}-\nu & \text { if } \left.w \in] \underline{w}, w_{e}\right] \\
\frac{\alpha}{1+\alpha+\phi \beta} \frac{(1+\tau \nu) w+\rho \pi+\Omega}{\tau w}-\nu & \text { if } \left.w \in] w_{e}, w_{n}\right] \\
0 & \text { if } w>w_{n}\end{cases} \\
& e^{*}= \begin{cases}0 & \text { if } w \leq w_{e} \\
\frac{\phi \beta}{1+\alpha+\phi \beta} \frac{(1+\tau \nu) w+\rho \pi+\Omega}{\rho}-\pi & \text { if } \left.w \in] w_{e}, w_{n}\right] \\
0 & \text { if } w>w_{n} .\end{cases}
\end{aligned}
$$

where $\left\{w_{n}, w_{e}, \underline{w}\right\} \in \mathbb{R}^{3+}$ and $w_{n}>w_{e}>\underline{w}>0$.

Proof. See the Appendix.

For low wages $(w \leq \underline{w})$, the time constraint binds hand in hand with the non-negativity constraint on educational investments. Women then have a maximal number of children and do not educate them. For higher wages $\left.\left.(w \in] \underline{w}, w_{e}\right]\right)$, fertility decreases with wages but the so-called trade-off between the quality and the quantity of children does not yet appear. What appears here is a trade-off between fertility and consumption. The trade-off between

\footnotetext{
${ }^{6}$ Obviously, $n \geq 0$ and $n \leq \frac{1}{\tau}$ cannot bind simultaneously.
} 


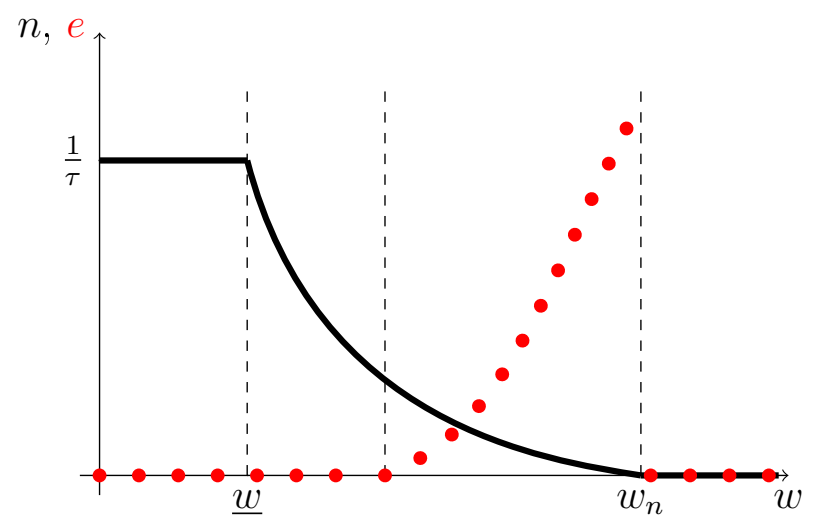

Figure 10: Quality quantity trade-off. Fertility $(n)$ in black, education $(e)$ in red

the quality and the quantity of children appears once $\left.w \in] w_{e}, w_{n}\right]$, and prevails as long as women have children. When wages become very high $\left(w^{f}>w_{n}\right)$, it is optimal to remain childless.

In this specification of the model, opportunity-driven childlessness acts as a barrier to the perpetuation of dynasties lying in the upper tail of the human capital distribution. It can reduce both the average level of human capital within society and inequalities in the distribution of human capital. To the best of our knowledge, this mechanism has never been quantified in the economic literature.

\subsection{Marriage and Childlessness}

Introducing endogenous marriage decisions into a model of fertility and consumption may lead to considerable complexity. ${ }^{7}$ For the sake of simplicity, we propose a model in which fertility and consumption decisions inside a marriage are made according to the model presented before. More precisely, we assume that inside a marriage, the woman decides how many children to have, if any, by maximizing her own utility function. This assumption is in line, for instance, with Regalia and Rios-Rull (2001). As most of the literature, we do not assume that men and women meet randomly on the marriage market; we specifically assume assortative mating in terms of education. Any person on the marriage market has more chances to be matched with a partner whose education level is close to his or her own educational level; we will refer to this phenomenon as educational assortativeness or educational homogamy.

\footnotetext{
${ }^{7}$ See Baudin, de la Croix, and Gobbi (2015) or Greenwood, Guner, and Knowles (2003) for representative examples.
} 
From the previous model, we know how a single woman behaves regarding fertility and childlessness. Let us denote $n_{s}$ her realized fertility, $w^{f}$ her wage, and $\Omega^{f}$ her non-labor income. We obtained that, except in Malthusian-type regimes, $\frac{d n_{s}}{d w^{f}} \leq 0$. Furthermore, whatever $\Omega^{f}>0, \frac{d n_{s}}{d \Omega^{f}} \geq 0$. If we denote $q\left(w^{f}, \Omega^{f}\right)$ the probability that a woman drawn randomly from the population is childless, then $\frac{d q\left(w^{f}, \Omega^{f}\right)}{d w^{f}}<0$ for low values of $w^{f}$ (higher wages protect against poverty-driven childlessness), while $\frac{d q\left(w^{f}, \Omega^{f}\right)}{d w^{f}}>0$ for high values of $w^{f}$ (higher wages increase the time cost of children and leads to opportunity-driven childlessness). We also learned that $\frac{d q\left(w^{f}, \Omega^{f}\right)}{d \Omega^{f}}<0$.

Let us now introduce married women. We assume that when married, a woman receives part of her husband's labor and non-labor income (denoted respectively $w^{m}$ and $\Omega^{m}$ ), as well as help from her husband to raise children. ${ }^{8}$ It implies that, compared to a single woman, a married woman has more non-labor income, while her time cost of raising children is smaller. This assumption is in line with Baudin, de la Croix, and Gobbi (2015).

We define the indirect utility of a woman $i$ enjoying a wage rate $w_{i}^{f}$ who is married to a man with a wage $w^{m}$ as:

$$
v_{i}^{M}=v^{S}\left(w_{i}^{f}\right)+\Delta^{f}\left(w_{i}^{f}, w^{m}\right)+\lambda_{i}^{f} .
$$

$v^{S}\left(w_{i}^{f}\right)$ is equal to the indirect utility that she would receive as a single woman, this value may be easily computed from the previous sections. $\Delta^{f}\left(w_{i}^{f}, w^{m}\right)$ denotes the economic surplus coming from marriage (additional income and time coming from the husband). It is straightforward that $\frac{d \Delta^{f}\left(w_{i}^{f}, w^{m}\right)}{d w^{m}}>0$, as the richer the potential husband, the higher the economic surplus coming from marriage, while $\frac{d \Delta^{f}\left(w_{i}^{f}, w^{m}\right)}{d w^{f}}<0$ as highly educated women rely less on marriage to increase their well-being. $\lambda_{i}$ is a love shock representing the quality of the union. We assume that it is drawn from a normal distribution such that:

$$
\lambda_{i}^{f} \sim \mathcal{N}\left(\frac{\overline{\lambda^{f}}}{\varepsilon+\left|w^{f}-w^{m}\right|}, \sigma^{f}\right) .
$$

$\left(\overline{\lambda^{f}}, \varepsilon\right) \in \mathbb{R}^{2+}$ are two scalars respectively ensuring the positivity of the average love shock and the existence of the latter for $w^{f}=w^{m}$. Let us point out that each pair $\left(w^{f}, w^{m}\right)$ has its own love shock process: the more homogamous a union in terms of wages (and thus education levels), the higher the expected quality of the match. We assume a constant variance across groups. We also assume that each potential couple may invest a costless infinitesimal amount of time living together in order to know their $\lambda_{i}$.

\footnotetext{
${ }^{8}$ Gobbi (2018) provides a semi-cooperative model of household decisions to explain how the time to raise children varies endogenously across households of different education levels.
} 
Computing the expected indirect utility of a woman with a wage $w_{i}^{f}$ who is matched with a partner with a wage $w^{m}$, we get that all women want to marry a priori, such that they all want to invest the small amount of time needed to receive the information about $\lambda_{i}$ :

$$
E v_{i}^{M}=v^{S}\left(w_{i}^{f}\right)+\Delta^{f}\left(w_{i}^{f}, w^{m}\right)+\frac{\overline{\lambda^{f}}}{\varepsilon+\left|w^{f}-w^{m}\right|}>v^{S}\left(w_{i}^{f}\right)
$$

Let us now introduce men. We assume that men can have children only if they are in a relationship. By symmetry with women, we assume that men are characterized by the following indirect utility $z_{i}^{M}$ :

$$
z_{i}^{M}=z^{S}\left(w_{i}^{m}\right)+\Delta^{m}\left(w_{i}^{f}, w^{m}\right)+\lambda_{i}^{m}
$$

$z^{S}\left(w_{i}^{m}\right)$ denotes the indirect utility of a single man earning $w^{m} \cdot{ }^{9}$ The surplus coming from marriage, $\Delta^{m}\left(w_{i}^{f}, w^{m}\right)$, originates from the possibility of having children, as well as from the additional income that the wife brings to the family. This surplus is reduced by the time the husband has to invest in raising children, as well as the potential transfer of income to the wife. For simplicity, we assume, as for women, that this surplus is necessarily positive. Regarding love shocks, men draw them from a distribution which is symmetric to that of women:

$$
\lambda_{i}^{m} \sim \mathcal{N}\left(\frac{\overline{\lambda^{m}}}{\varepsilon+\left|w^{f}-w^{m}\right|}, \sigma^{m}\right)
$$

with $\left(\overline{\lambda^{m}}, \varepsilon\right) \in \mathbb{R}^{2+}$. We let the mean and the variance of love shocks diverge between men and women, as the literature on gender differences in preferences has documented systematic gender differences in preferences regarding for example risk aversion, taste for competition, and family ties. ${ }^{10}$

As for women, we get that all men want to marry ex ante. Computing the expected indirect utility of a man with a wage $w_{i}^{m}$ who is matched with a partner with a wage $w^{f}$, we get that:

$$
E z_{i}^{M}=z^{S}\left(w_{i}^{m}\right)+\Delta^{m}\left(w_{i}^{m}, w^{f}\right)+\frac{\overline{\lambda^{m}}}{\varepsilon+\left|w^{f}-w^{m}\right|}>z^{S}\left(w_{i}^{m}\right)
$$

\section{Realized shocks and marriage rates}

We first assume that a marriage will occur only if, after the realization of the love shock,

\footnotetext{
${ }^{9}$ We implicitly assume here that the utility function of men is the same as that of women in the previous sections: $u^{m}\left(c^{m}, n\right)$ with $u^{m}\left(w^{m}+\Omega, 0\right) \in \mathbb{R}$ representing the indirect utility of a single man.

${ }^{10}$ Hiller and Baudin (2016) and Baudin and Hiller (2019) extensively discuss the interactions between gender differences in preferences and marital behaviors.
} 
both partners still want to marry. Then, assuming that the law of large numbers applies, we can compute the proportion of women with a wage $w^{f}$ matched with a man with $w^{m}$ who have decided not to marry because they received too bad a love shock. Let us denote the latter, $p^{f}\left(w^{f}, w^{m}\right)$ :

$$
p^{f}\left(w^{f}, w^{m}\right) \equiv \operatorname{Prob}\left(\lambda_{i}^{f}<-\Delta^{f}\left(w^{f}, w^{m}\right)\right)=\frac{1}{\sigma^{f} \sqrt{2 \pi}} \int_{-\infty}^{-\Delta^{f}\left(w^{f}, w^{m}\right)} e^{-\frac{1}{2} \frac{x-\frac{1}{\varepsilon+\left|w^{f}-w^{m}\right|}}{\left(\sigma^{f}\right)^{2}}} d x
$$

By symmetry, we get that the proportion of men with a wage $w^{m}$ matched with a woman with $w^{f}$ who have decided not to marry because they received too bad a love shock is:

$$
p^{m}\left(w^{m}, w^{f}\right) \equiv \operatorname{Prob}\left(\lambda_{i}^{m}<-\Delta^{m}\left(w^{m}, w^{f}\right)\right)=\frac{1}{\sigma^{m} \sqrt{2 \pi}} \int_{-\infty}^{-\Delta^{m}\left(w^{m}, w^{f}\right)} e^{-\frac{1}{2} \frac{x-\frac{1}{\varepsilon+\left|w^{f}-w^{m}\right|}}{\left(\sigma^{m}\right)^{2}}} d x .
$$

Let us assume that the number of education categories is discrete and let us denote $\tilde{w}$ the number of wage/education categories in the economy. We get that the proportion of married women, $m$, is the following:

$$
m=\sum_{w^{f}=1}^{\tilde{w}} \sum_{w^{m}=1}^{\tilde{w}} \xi\left(w^{f}, w^{m}\right)\left[1-p^{f}\left(w^{f}, w^{m}\right)\right]\left[1-p^{m}\left(w^{m}, w^{f}\right)\right]
$$

where $\xi\left(w^{f}, w^{m}\right)$ denotes the proportion of women of type $w^{f}$ matched with a man of type $w^{m}$. Equation (6) shows how marriage rates, and therefore childlessness rates, may be influenced by the degree of educational homogamy. A first straightforward effect of increasing homogamy is to reduce the average distance between $w^{f}$ and $w^{m}$, which increases the average quality of unions and marriage rates in turn. In technical terms, $\xi\left(w^{f}, w^{m}\right)$ increases for $w^{f}$ close enough to $w^{m}$, but decreases for other values of $w^{f}$. It implies that, everything else equal, the proportion of couples receiving bad love shocks then recedes, and more couples are willing to marry. ${ }^{11}$

Nevertheless, this composition effect may be counterbalanced by an indirect effect of rising homogamy on the average marriage surplus. Indeed, low-educated women are matched with less educated men, which reduces their marriage surplus, while highly educated women are more often matched with highly educated men, which increases their surplus. ${ }^{12}$ The same is true for men. Low-educated men are more often matched with low-educated women

\footnotetext{
${ }^{11}$ This effect appears as the movement of the exponential part of the cumulative distribution function of love shocks for men and women.

${ }^{12}$ In Equation 6, this effect corresponds to the variations of $\Delta^{f}\left(w^{f}, w^{m}\right)$.
} 
for whom the risk of poverty-driven childlessness is higher, while highly educated men are more often matched with highly educated women who are also likelier to remain childless because of economic opportunities. These indirect effects have an undetermined impact on $m$, but they are second-order effects and thus, even if negative, they cannot dominate the direct composition effect. Since compared to singleness, marriage protects against povertydriven childlessness and reduces the incentives for not having children among highly educated women, an increase in homogamy therefore decreases childlessness.

We have analyzed the effect of rising educational homogamy under the implicit assumption that the average levels of education among men and women remains constant. As discussed for instance by Iyigun and Lafortune (2016) in the case of the US and by Van Bavel (2012) in the case of Europe, an increase in educational homogamy has emerged hand in hand with an increase in female education, and thus in $w^{f}$. When the average level of $w^{f}$ increases, the marriage surplus for women is again potentially reduced, which contributes to making the indirect effect discussed in the previous paragraph more negative. As a result, the increase in marriage rates due to higher educational homogamy is again mitigated. In addition, as women are now more educated, fewer of them are childless because of poverty, while more of them are childless because of improved economic opportunities. Knowing this, the final impact of a rise in educational homogamy due to an increase in women's education is ambivalent: it depends on the initial intensity of poverty and the initial level of educational homogamy. From one country to another, the impact of rising educational homogamy may be different.

Interestingly enough, we have given men a rather limited role in fertility decisions inside a marriage; nevertheless, we have shown how their marriage decisions strongly affect childlessness. By refraining (resp. easing) the marriage of low-educated women, they make poverty-driven childlessness increase (resp. recede). The opposite is true regarding highly educated women and opportunity-driven childlessness: by alleviating the time cost of having children, they contribute to limiting the positive link that exists between women's educational attainment and childlessness among highly educated women. As a result, societies strongly promoting gender equity regarding wages and fathers' involvement in children's education are more prone to limit opportunity-driven childlessness.

\section{Conclusion}

Throughout this chapter, we have shown why childlessness matters in itself. It has mainly provided additional, different insights to those coming from the intensive margin of fertility. 
We have shown that, historically, childlessness rates were large among the wealthiest groups. The reasons are still to be explained and contrast with the outcomes of a Malthusian model of fertility, which is usually used for historical times. Nowadays, childlessness can also be large both in developed and developing countries. Nevertheless, contrary to developed countries, high childlessness rates co-exist with high fertility along the intensive margin (high fertility of mothers) in developing countries. This difference mainly comes from the opposite effect of economic development on the burden of poverty and the economic opportunities offered to women.

We have shown theoretically that accounting for poverty-driven childlessness matters to correctly evaluate the impact that development policies, reputed to reduce fertility, might

have on the latter. Indeed, such policies might reduce childlessness rates and hence lead to an increase in overall fertility rates. Accounting for opportunity-driven childlessness in a quantity-quality model brings the result that childlessness can act as a way to reduce inequalities in the distribution of human capital, a mechanism which still has to be explored quantitatively.

Introducing marriage into an endogenous fertility model that accounts for childlessness also provides new insights: higher educational homogamy per se decreases childlessness as it favors marriage. Nevertheless, as educational homogamy is most of the time accompanied by a rise in female education, it may also be associated with increases in childlessness in the data.

\section{References}

Aaronson, Daniel, Fabian Lange, and Bhashkar Mazumder. 2014. "Fertility Transitions along the Extensive and Intensive Margins." American Economic Review 104 (11): 3701-24 (November).

Bardet, Jean-Pierre. 1983. Rouen au XVII et XVIII siècles. Paris: SEDES.

Baudin, Thomas. 2011. "Family policies: what does the standard endogenous fertility model tell us?" Journal of Public Economic Theory 13 (4): 555-593.

—. 2012. "The Optimal Trade-Off Between Quality and Quantity with Unknown Number of Survivors." Mathematical Population Studies 19 (2): 94-113.

Baudin, Thomas, David de la Croix, and Paula E. Gobbi. 2015. "Fertility and Childlessness in the US." American Economic Review 105 (6): 1852-1882. 
- 2019. "Endogenous childlessness and stages of development." Forthcoming in the Journal of the European Economic Association.

Baudin, Thomas, and Victor Hiller. 2019. "On the Dynamics of Gender Differences in Preferences." forthcoming.

Baudin, Thomas, and Koyel Sarkar. 2018. "Education and childlessness in India." Université catholique de Louvain.

Baudin, Thomas, and Robert Stelter. 2018a. "A history of childlessness in Germany." mimeo.

—. 2018b. "Rural exodus and fertility in times of industrialization." mimeo.

Becker, Gary S. 1960. "An Economic Analysis of Fertility." In Demographic and Economic Change in Developed Countries, NBER Chapters, 209-240. National Bureau of Economic Research, Inc.

Berrington, Anna. 2017. "Childlessness in the UK." In Childlessness in Europe: Contexts, Causes, and Consequences, by Michaela Kreyenfeld Dirk Konietzka, pp. 57-76.

Bhalotra, Sonia, Atheendar Venkataramani, and Selma Walther. 2018. "Fertility and Labor Market Responses to Reductions in Mortality." mimeo.

Canning, David, Sangeeta Raja, and Abdo Yazbeck. 2015. Africa's demographic transition: dividend or disaster? The World Bank.

De Vries, Jan. 2008. The Industrious Revolution: Consumer Behavior and the Household Economy, 1650 to the Present. Cambridge: Cambridge University Press.

de la Croix, David, and Sandra Brée. 2019. "Key Forces Behind the Decline of Fertility Lessons from Childlessness in Rouen before the Industrial Revolution." forthcoming in Cliometrica.

de la Croix, David, and Matthias Doepke. 2003. "Inequality and Growth: Why Differential Fertility Matters." American Economic Review 93 (4): 1091-1103.

de la Croix, David, and Omar Licandro. 2015. "The Longevity of Famous People from Hammurabi to Einstein." Journal of Economic Growth 20:263-303.

de la Croix, David, and Aude Pommeret. 2018. "Childbearing Postponement, its Option Value, and the Biological Clock." CEPR Discussion Paper, Centre for Economic Policy Research.

de la Croix, David, Eric B. Schneider, and Jacob Weisdorf. 2018. "“Decessit sine prole" - Childlessness, Celibacy, and Survival of the Richest in Pre-Industrial England." LSE Economic History Working Papers 276/2018. 
de la Croix, David, and Marie Vander Donckt. 2010. "Would Empowering Women Initiate the Demographic Transition in Least Developed Countries?" Journal of Human Capital 4 (2): 85-129.

Gobbi, P. E., and M. Goñi. 2017, July. "Childless Aristocrats: Fertility, Inheritance, and Persistent Inequality in Britain (1650-1882)." CEPR Discussion Paper, Centre for Economic Policy Research.

Gobbi, Paula E. 2013. "A model of voluntary childlessness." Journal of Population Economics 26 (3): 963-982 (July).

—. 2018. "Childcare and commitment within households." Journal of Economic Theory 176:503-551.

Greenwood, Jeremy, Nezih Guner, and John A. Knowles. 2003. "More on Marriage, Fertility, and the Distribution of Income." International Economic Review 44 (3): 827-862.

Habakkuk, H. J. 1950. "Marriage Settlements in the Eighteenth Century." Transactions of the Royal Historical Society 32:15-30.

Hiller, Victor, and Thomas Baudin. 2016. "Cultural transmission and the evolution of gender roles." Mathematical Social Sciences 84:8-23.

Hollingsworth, T. H. 1964. "The Demography of the British Peerage." Population Studies, vol. Supplement.

— 2001. "Hollingsworth Genealogical Data on the British Peerage". Database. Redigitised from handwritten original index sheets and archived by the Cambridge Group for the History of Population and Social Structure.

Hollingsworth, Thomas H. 1965. The Demography of the British Peerage. London: Population Investigation Committee, LSE.

Iftikhar, Zainab. 2018. "The effect of norms on fertility and its implications for the quantityquality tradeoff in Pakistan." IRES, Université catholique de Louvain.

Iyigun, Murat, and Jeanne Lafortune. 2016. "Why wait? A century of education, marriage timing and gender roles." mimeo.

Jones, Larry E., Alice Schoonbroodt, and Michèle Tertilt. 2010. Chapter Fertility Theories: Can They Explain the Negative Fertility-Income Relationship? of Demography and the Economy, edited by John B. Shoven, 43-100. Chicago: University of Chicago Press.

Kreyenfeld, Michaela, and Konietzka Dirk. 2017. "Childlessness in East and West Germany: Long-term trends and social disparities, in Kreyenfeld, Michaela, and Dirk Konietzka (Eds.)." Springer, pp. 97-114. 
Leridon, Henri. 2008. "A New Estimate of Permanent Sterility by Age: Sterility Defined as the Inability to Conceive." Population Studies 62 (1): 15-24.

Malthus, Thomas. 1807. An Essay on the Principle of Population. Fourth Edition. London: T. Bensley.

Poston, Dudley L., and Katherine Trent. 1982. "International Variability in Childlessness: A Descriptive and Analytical Study." Journal of Family Issues 3 (4): 473-491.

Regalia, Ferdinando, and Jose-Victor Rios-Rull. 2001. "What accounts for the increase in the number of single households?" University of Pennsylvania, mimeo.

Sadler, Michael Thomas. 1830. The Law of Population - in disproof of the superfecundity of human beings, and developing the real principle of their increase. London: John Murray.

Tietze, Christopher. 1957. "Reproductive Span and Rate of Reproduction Among Hutterite Women." Fertility and Sterility 8 (1): 89-97.

Turra, Cassio M, and Bernardo L Queiroz. 2005. "Before it's too late: demographic transition, labor supply, and social security problems in Brazil." United Nations Expert Group Meeting on Social and Economic Implications of Changing Population Age Structures. Departamento de Assuntos Econômicos e Sociais, Divisão de População México.

Van Bavel, Jan. 2012. "The reversal of gender inequality in education, union formation and fertility in Europe." Vienna Yearbook of Population Research, pp. 127-154.

Van de Walle, Etienne, and Francine Van de Walle. 1972. "Allaitement, stérilité et contraception : les opinions jusqu'au XIXe siècle." Population 27 (4): 685-701.

Wrigley, Edward Anthony, R S Davies, James Oeppen, and Roger Schofield. 1997. English Population History from Family Reconstitution: 1580-183\%. Cambridge: Cambridge University Press. 


\section{A Proof of Proposition 1}

The aim of this appendix is not to determine how people behave for any couple $\{w, \Omega\}$ but to show that there exists a non-empty state space $\mathcal{H}$ such that agents behave the way described in Proposition 1. To do so, we first solve the maximization problem described in the core of the chapter under the following constraint: $n \in] 0, \frac{1}{\tau}[$ and $e>0$. In this pure interior regime, we get that:

$$
\begin{aligned}
c^{*} & =\frac{(1+\tau \nu) w+\rho \pi+\Omega}{1+\alpha+\phi \beta} \\
n^{*} & =\frac{\alpha}{1+\alpha+\phi \beta} \frac{(1+\tau \nu) w+\rho \pi+\Omega}{\tau w}-\nu \\
e^{*} & =\frac{\phi \beta}{1+\alpha+\phi \beta} \frac{(1+\tau \nu) w+\rho \pi+\Omega}{\rho}-\pi
\end{aligned}
$$

From this, we can deduce the level of wages under which such an interior regime may exist and prevail. We get that $n^{*}>0 \Longleftrightarrow w<\frac{\alpha(\rho \pi+\Omega)}{(1+\phi \beta) \tau \nu-\alpha} \equiv w_{n} ; e^{*}>0 \Longleftrightarrow \frac{(1+\alpha) \rho \pi-\phi \beta \Omega}{\phi \beta(1+\tau \nu)} \equiv w_{e}$.

Simple computations indicate that $w_{n}>w_{e} \Longleftrightarrow \Omega<\frac{(\tau \nu-\alpha) \rho \pi}{\tau \phi \beta \nu} \equiv \hat{\Omega}$. Let's now assume that $\Omega<\hat{\Omega}$, we get that $\forall w \in] w_{e}, w_{n}[$, the purely interior regime as described in Equations 7 to 9 prevails. For any $w \geq w_{n}, n^{*}=0$ implying $e^{*}=0$ by definition and so $c^{*}=w+\Omega$.

We now have to analyze cases where $w \leq w_{e}$. In this situation, we have to solve the maximization problem under the constraint that $e^{*}=0$ and $\left.n^{*} \in\right] 0, \frac{1}{\tau}[$. In this situation, we obtain that:

$$
\begin{aligned}
c^{*} & =\frac{(1+\tau \nu) w+\Omega}{1+\alpha} \\
n^{*} & =\frac{\alpha}{1+\alpha} \frac{(1+\tau \nu) w+\Omega}{\tau w}-\nu \\
e^{*} & =0
\end{aligned}
$$

A simple inspection of Equation 11 indicates that $n^{*} \leq \frac{1}{\tau} \Longleftrightarrow w \geq \frac{\alpha \Omega}{1+\tau \nu} \equiv \underline{w}$. A condition of existence for this regime is that $\underline{w}<w_{e}$ what is satisfied if $\Omega>\frac{\rho \pi}{\phi \beta} \equiv \tilde{\Omega}$. Let's assume that this condition on $\Omega$ is fulfilled too. We then get that $\left.\forall w \in] \underline{w}, w_{e}\right]$, the optimal behavior of our representative agent is represented by the set of Equations 10 to 12. The last situation 
we have to explore is $w \leq \underline{w}$. In this situation, as $n^{*}=\frac{1}{\tau}$, $e^{*}=0$, we get:

$$
\begin{aligned}
c^{*} & =\Omega \\
n^{*} & =\frac{1}{\tau} \\
e^{*} & =0
\end{aligned}
$$

The advised reader would have noticed that we had to assume $\Omega>\tilde{\Omega}$ and $\Omega<\hat{\Omega}$. For Proposition 1 to be valid, there should exist a state-space allowing the condition $\tilde{\Omega}<\hat{\Omega}$ to be fulfilled. We obtain that:

$$
\tilde{\Omega}<\hat{\Omega} \Longleftrightarrow \frac{\tau \nu-\alpha}{\tau \nu}<1
$$

what is always satisfied. We then get that $\forall \Omega \in] \tilde{\Omega}, \hat{\Omega}[$, the representative agent behaves as described in Proposition 1 what validates this latter. 